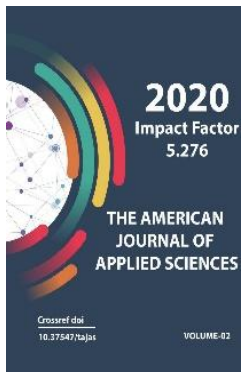

\title{
Pedagogical Tests As An Element Of Types Of Pedagogical Technologies
}

\author{
Atoeva Mehriniso Farhodovna
}

Associate Professor Of The Department Of Physics, Bukhara State University, Uzbekistan

Journal Website:

http://usajournalshub.c

om/index,php/tajas

Copyright: Original content from this work may be used under the terms of the creative commons attributes 4.0 licence.

\section{ABSTRACT}

The question of the learning objectives of the new pedagogical technology should be considered in conjunction with the problem of transferring the learning objective to the test task, and it is necessary to determine the level of achievement of the goal. Positive qualities in testing can be demonstrated only under the conditions in which qualitative tests are used. However, there are certain difficulties in creating quality tests. This is primarily a process that stems from the experience and knowledge of designing quality tests among teachers.

\section{KEYWORDS}

Tests, new pedagogical technology, learning objectives, teachers and students

\section{INTRODUCTION}

While testing is not new to the current generation of teachers, it is a much older form of pedagogical technology among other types of tasks. In many developed countries of the world, tests have a special place in the education system.
A pedagogical test consists of a set of short, interconnected learning tasks that allow an assessment of the goals and content of a subject or its section or other aspects of students. Most test assignments consist of a series of questions and possibly captured 
answers, one of which will be correct and the rest will be incorrect but seem to be correct.

\section{MATERIALS AND METHODS}

Pedagogical tests are the most appropriate method of assessing knowledge and have several advantages:

- The test covers the entire main content of the subject (the exam ticket contains only $4-5 \%$ of the controlled educational material);

- All teachers answer the same test questions which allow them to compare their knowledge;

- Criteria for objective assessment of students' knowledge will increase;

- Testing allows you to make a more accurate assessment of students' knowledge using a pre-developed scale, which is the same for everyone;

- Teachers spend less time monitoring students' knowledge;

- Conditions are created to measure the possibility of increasing knowledge at any time;

- Test control is convenient for computer automation.

In general, the test method is more technological; it increases the quality of mastering knowledge in control, increases the productivity of the teaching staff and provides a deep and comprehensive delivery of the training program. Finally, the test method takes less time than traditional methods of knowledge control. However, the process of pedagogical testing also has a number of shortcomings, such as depriving the student of the opportunity to describe their answers independently (orally or in writing). And the psychological activity of the student is not the simple answer; the student cannot show their knowledge and personality in the answers to the questions posed in the test.

\section{RESULTS AND DISCUSSIONS}

Some universities require students to submit written answers to certain questions during tests. Forms of test assignments in pedagogical tests may include:

As a closed assignment with a single correct answer.

$>$ Closed assignments with multiple possible correct answers.

$>$ Open assignments consisting of a single word (or words) omitted sentence.

$>$ Tasks to determine the correlation (compatibility).

$>$ Tasks to determine the correct sequence (in their execution it is necessary to speak of random words).

$>$ Tasks to determine the depth of knowledge in certain disciplines.

$>$ Tasks for finding and solving numbers, including determining the method of finding a series of numbers and defining it in a certain order.

$>$ Problem-solving tasks (mathematics, physics, etc.).

$>$ Tasks to understand drawings and diagrams.

$>$ Tasks to determine the ratio of forms.

$>$ Assignments to determine the level of assimilation of the received information.

$>$ Tasks to distinguish synonyms and antonyms.

$>$ Assignments to analogies (exact similarity).

$>$ Tasks to follow instructions.

> Tasks to determine knowledge.

$>$ Language assignments and other assignments.

Closed tests, open tests, tests to determine compliance, and tests to determine correct 
consistency are the most widely used in the educational process of educational institutions. If the student can answer freely, the test task will have an open form. Closed test assignments consist of a task confirmation and several answers, one of which is correct, the rest are similar, but incorrect. The number of answers offered can range from two to five and more. The essence of conformity tests is based on the need to determine the compatibility of one polynomial element with another polynomial element.
These assignments should also be structured on the basis of an instruction consisting of the word to determine compliance. To determine the correct consistency, the test is used primarily to assess the level of professional readiness of the assignments to determine the accuracy of the sequence. They are used to check that actions, discussions, calculations are mastered in sequence (consistency). Instructions are given to determine the correct sequence during the test.

\section{Develop Test Assignments For Different Levels Of Mastery}

(Only One Element Of The Study Material)

\begin{tabular}{|c|c|c|}
\hline & Mastering Level & Definition \\
\hline 1. & Level of learning & $\begin{array}{l}\text { The level of learning activity is the ability to perceive } \\
\text { previously learned information about an object or } \\
\text { process or action, to distinguish it from misuse. }\end{array}$ \\
\hline 2. & Reproductive level & $\begin{array}{l}\text { The students are required to respond independently, } \\
\text { memorizing previously learned actions, rules, } \\
\text { methods, algorithms in a variety of typical conditions, } \\
\text { which do not require the creation of new information. } \\
\text { While the knowledge to be tested has a knowledge- } \\
\text { repetitive nature, the thinking activity has an } \\
\text { algorithmic nature. }\end{array}$ \\
\hline 3. & Productive level & $\begin{array}{l}\text { The students are required to respond independently to } \\
\text { the acquired knowledge in order to solve a non-typical } \\
\text { task and obtain subjectively new information. Has the } \\
\text { ability to replicate knowledge. It is a heuristic activity } \\
\text { created or modified in the process of action itself, not } \\
\text { according to a ready-made copy or rule. For example, } \\
\text { the solution of a specific task according to a certain } \\
\text { general method or the implementation of a specific } \\
\text { (specific) project is carried out by independent } \\
\text { adaptation to the conditions of the problem. This can } \\
\text { only be solved in general terms. In this case, } \\
\text { knowledge acquires a cognitive-skill character. }\end{array}$ \\
\hline 4. & Creative level & If the purpose of the activity in question is known only \\
\hline
\end{tabular}




\begin{tabular}{|l|l|}
\hline & $\begin{array}{l}\text { in general form, if there are relevant circumstances } \\
\text { and actions leading to the purpose of the claim, this is } \\
\text { the general effect of the creative type, resulting in } \\
\text { new objective information. The student moves } \\
\text { without rules, but creates new rules of behavior in } \\
\text { certain areas. }\end{array}$
\end{tabular}

\section{CONCLUSION}

In conclusion, the use of pedagogical tests in the learning process plays an important role in increasing the effectiveness of teaching. The introduction of all forms of pedagogical tests in educational institutions will not only strengthen the knowledge and skills acquired by students, but also expand their worldview, motivate them to recall and learn from other disciplines.

\section{REFERENCES}

1. M.F. Atoyeva. Interdisciplinary relations in physics course at specialized secondary education. The Way of Science.-Volgograd, 2016. №9 (31). - P.22-24.

2. M.F. Atoyeva. The significance of periodicity at teaching physics. The Way of Science. - Volgograd, 2016. -№ 10 (32). - P.62-64.

3. M.F. Atoyeva. Use of Periodicity in Teaching Physics. Eastern European Scientific Journal. -DüsseldorfGermany, 2017. № 4. -P. 35-39.

4. M.F. Atoyeva. Didactic foundations of inter-media relations in the training of university students. International Scientific Journal. Theoretical \& Applied Science. p-ISSN: 2308-4944 (print) e-ISSN: 2409-0085 (online).
Year: 2020 Issue: 06 Volume: 86, P. 124.

5. M.F. Atoyeva, R. Safarova. Pedagogical integration as a means of forming professionally important qualities among students of a medical university. Academicia. ISSN: 2249-7137 Vol. 10, Issue 8, August 2020. Impact Factor: SJIF $2020=7.13$ ACADEMICIA: An International Multidisciplinary Research Journal https://saarj.comэ.

6. Use of alternative energy sources at the natural sciences lessons. SK Kakhkhorov, HO Juraev, MF Atoeva. The Way of Science. 36, 148

7. Atoeva M.F. Periodicity of teaching physics. Postgraduate student and researcher.- Moscow, 2010. -№6. - p. 41-43.

8. S.K.Kaxxorov, Atoeva M.F. Periodicity in the quality of pedagogical laws of physical training. Pedagogical sciences. -Moscow, 2010. -№ 6. - p. 56-59

9. Muhamadjonovna, S. D. (2020). The key concepts of forming sociolinguistic competence of future English language specialists. Asian Journal of Multidimensional Research (AJMR), 9(5), 118-121.

10. Muhamadjonovna, S. D. (2020). The development of sociolinguistic 
competence of future English language teachers through computer technologies.

11. HayitovYozil Kosimovich, JumaeyaTozagul Azamovna, ToshbekovNurbek Ahmadovich, NazarovaFiruza Ahmedjanovna (2020), The Formation of Water CollectorResources Drainage Network of Zarafshan Oasis and the Questions of Recycling: May-June. ISSN: 0193-4120

Page No. 27380-27385 